\title{
Setup Reduction Approaches for Machining
}

Federal Manufacturing \& Technologies

\author{
L. K. Gillespie
}

KCP-613-5881

SEIVED

Published April 1997

MAY 131997

OSTI

Approved for public release; distribution is unlimited.

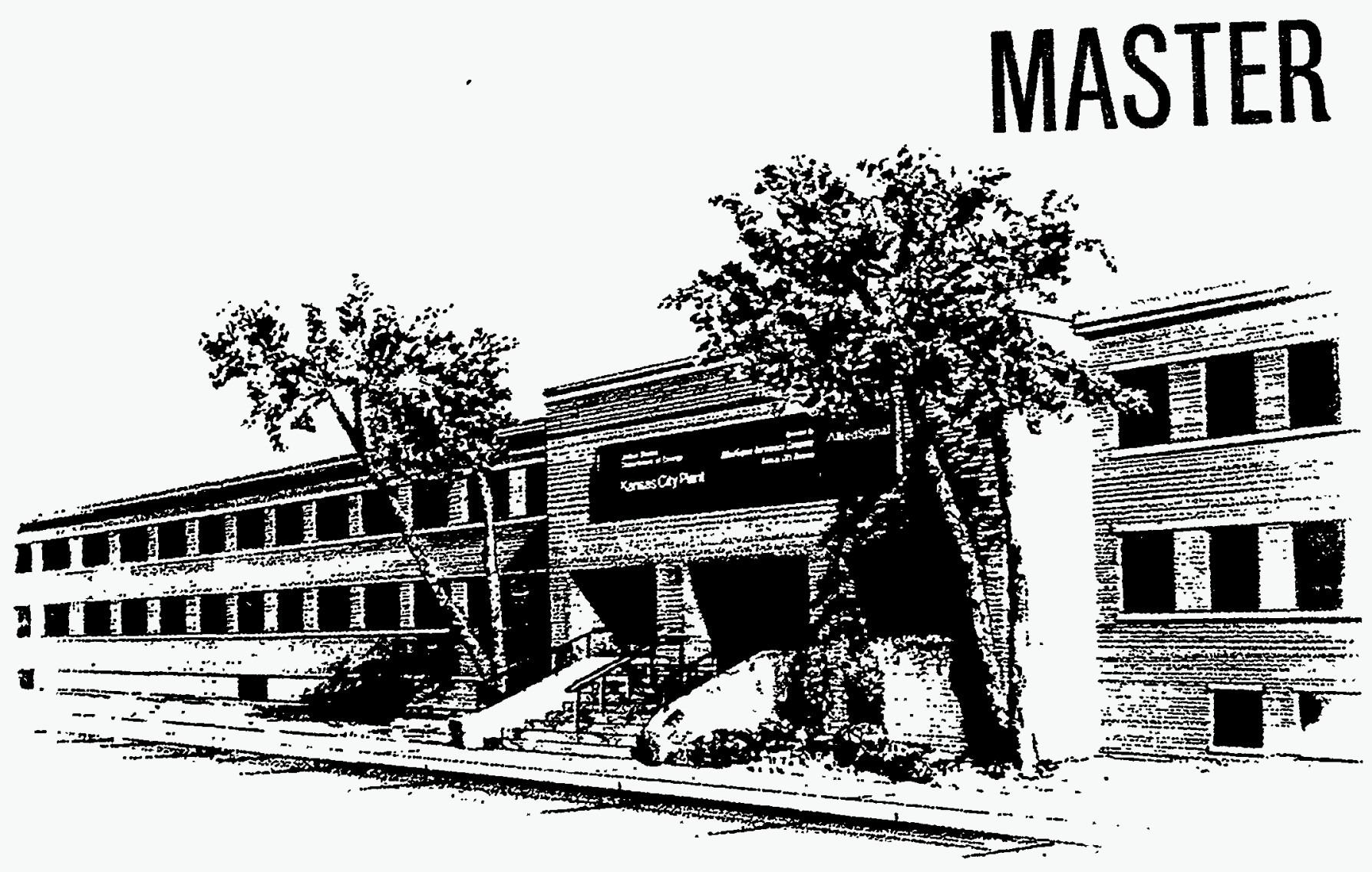

Prepared Under Contract Number DE-ACO4-76-DP00613 for the United States Department of Energy 


\section{DISCLAIMER}

This report was prepared as an account of work sponsored by an agency of the United States Government. Neither the United States Government nor any agency thereof, nor any of their employees, makes any warranty, express or implied, or assumes any legal liability or responsibility for the accuracy, completeness, or usefulness of any information, apparatus, product, or process disclosed, or represents that its use would not infringe privately owned rights. The views and opinions of authors expressed herein do not necessarily state or reflect those of the United States Government or any agency thereof.

All data prepared, analyzed and presented has been developed in a specific context of work and was prepared for internal evaluation and use pursuant to that work authorized under the referenced contract. Reference herein to any specific commercial product, process or service by trade name, trademark, manufacturer, or otherwise, does not necessarily constitute or imply its endorsement, recommendation, or favoring by the United States Government, any agency thereof or AlliedSignal Inc.

Printed in the United States of America.

This report has been reproduced from the best available copy.

Available to DOE and DOE contractors from the Office of Scientific and Technical Information, P. O. Box 62, Oak Ridge, Tennessee 37831; prices available from (615) 576-8401, FTS 626-8401.

Available to the public from the National Technical Information Service, U. S. Department of Commerce, 5285 Port Royal Rd., Springfield, Virginia 22161.

A prime contractor with the United States Department of Energy under Contract Number DE-ACO4-76-DP00613.
AlliedSignal Inc. Federal Manufacturing \& Technologies P. O. Box 419159 Kansas City, Missouri 64141-6159 


\section{DISCLAIMER}

This report was prepared as an account of work sponsored by an agency of the United States Government. Neither the United States Government nor any agency thereof, nor any of their employees, make any warranty, express or implied, or assumes any legal liability or responsibility for the accuracy, completeness, or usefulness of any information, apparatus, product, or process disclosed, or represents that its use would not infringe privately owned rights. Reference herein to any specific commercial product, process, or service by trade name, trademark, manufacturer, or otherwise does not necessarily constitute or imply its endorsement, recommendation, or favoring by the United States Government or any agency thereof. The views and opinions of authors expressed herein do not necessarily state or reflect those of the United States Government or any agency thereof. 


\section{DISCLAIMIER}

\section{Portions of this document may be illegible in electronic image products. Images are produced from the best available original document.}


KCP-613-5881

Distribution Category UC-700

Approved for public release; distribution is unlimited.

\section{SETUP REDUCTION APPROACHES}

FOR MACHINING

L. K. Gillespie

Published April 1997 


\section{CONTENTS}

Section

Page

Abstract.................................................................................................................

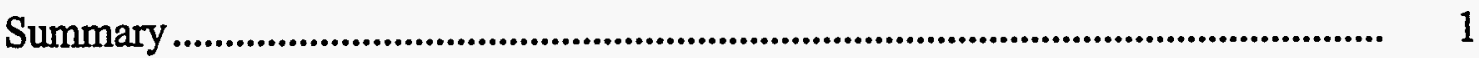

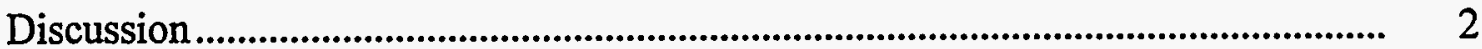

Scope and Purpose ......................................................................................... 2

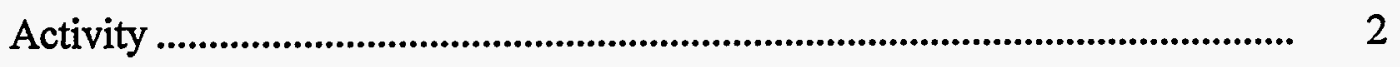

Background ............................................................................................. 2

Setup Time Reduction Considerations...................................................... 3

Setup Reductions Applicable to Machining ................................................ 4

Setup Reduction Constraints for FM\&T Applications ................................. 11

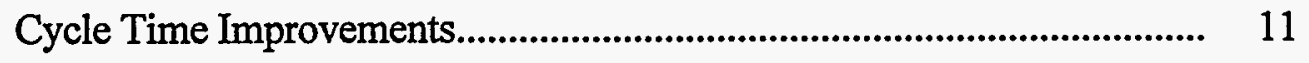

Accomplishments........................................................................................ 12

Future Work ....................................................................................................... 13

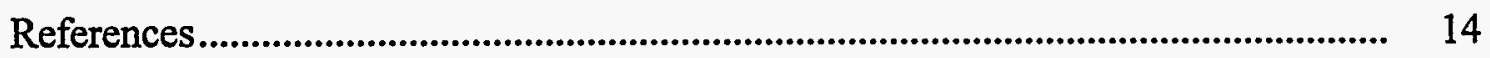




\begin{abstract}
Rapid setup is a major benefit to rapid production and cost reduction efforts. This report reviews rapid setup as it relates to machining operations and to the Kansas City Plant of AlliedSignal Federal Manufacturing \& Technologies (FM\&T).
\end{abstract}

\title{
SUMMARY
}

Rapid setup is a common improvement approach in press working operations such as blanking and shearing. It has paid major dividends in the sheet metal industry. It also has been a major improvement thrust for high-production machining operations. However, the literature does not well cover all the setup operations and constraints for job shop work. This review provides some insight into the issues involved. It highlights the floor problems and provides insights for further improvement. The report is designed to provide a quick understanding of the issues. 


\section{DISCUSSION}

\section{SCOPE AND PURPOSE}

When this study was initiated, it was apparent that quick turnaround was required on all fabrication efforts to meet customer needs. In machining applications, few technical approaches were available, and the ones that were being introduced had not been evaluated for applicability at FM\&T. The purpose of this project was to evaluate what the large-part machining department could do to have quicker turnaround. For several reasons, it was important to broaden the review to all machining operations and departments, yet still maintain a clear assessment applicable to each department's needs. This brief review will provide an overview of both industry technology and technology issues applicable to FM\&T.

This project was not funded to perform actual time studies, purchase equipment, or change actual processes. It is a study to define feasibility and issues.

\section{ACTIVITY}

The following pages summarize a review of the concepts available to improve turnaround time in machining.

\section{Background}

Quick turnaround production and setup reduction are almost synonymous terms. For the purpose of this report, we will treat each as equivalent. Staff preparation and availability are one of the major differences in these two concepts. This study did not address the issue of staff availability at time of need.

Setup reduction involves several elements:

- Workpiece Issues

- Work Holding Issues

- $\quad$ Cutting Tool Issues

- $\quad$ Quick Change Tool Holders

- Tool Positioning Issues

- $\quad$ Part Inspection Issues

- Machine Capabilities

- $\quad$ Process Approaches

- Machine Dedication

- Unmanned Operations

- $\quad$ Provisioning

- $\quad$ N/C Tape Issues

- Maintenance of Machines and Tooling 
In addition to each technology area mentioned in the above list, part volume, lot size, quality expectations, part design ${ }^{1}$ (shape and tolerances), part design change frequency, and staff proficiency also greatly affect the viability of the technology. These latter issues will be discussed after the technologies are described and analyzed.

When the project began, the literature had few references to effective setup reduction technology. A new lathe-chucking approach using Hirth coupling had just been introduced which held the promise of allowing large chucks to be changed in a matter of seconds while maintaining part accuracies of 0.0002-0.0005 inch. That represented a major advance in potential to reduce setup for some lathes. It also happened to be a very expensive issue when many different machines and product designs were involved.

Since project initiation, many new approaches have been introduced and made commercially viable. In fact, for every area in the above list, some improvements have been introduced by industry.

\section{Setup Time Reduction Considerations}

The workpiece has a major influence on what can be done to reduce setup times. FM\&T machines parts from barstock, forgings, and castings. The production requirements in most cases today are to produce a single lot of parts with the possibility that another lot or quantity of parts may be made in six months or more. While some families of parts and families of machines exist, the plant is capable of and required essentially to machine about any size and configuration conceivable. Parts made on screw machines are no issue as they are clearly a family and are processes with some minimal amount of setup issues. Advances can still be made there, but the biggest gains of the plant are in the other parts.

For parts in general, part geometry, surface finishes, and part tolerances generally require multiple setups on each part to produce the required tolerances.

The FM\&T plant has used group technology approaches to classify its parts and to design appropriate fabrication departments. Due to the limited quantity of parts within a single family, the benefits of group technology have been smaller than for plants having thousands of machined part designs.

The FM\&T product families that require machining include the following:

- Screw machine parts

- Miniature lathe parts

- Small lathe parts

- Small milled parts

- Wire EDMed parts

- Machined castings

- Medium lathe parts
Small turned shafts and pins

0.010-0.125 inch diameters

0.125-1.25 inch diameters

Hand size and smaller

0.250 inch to 12 inch shapes

Hand sized and larger milled shapes

2-6 inch diameters 
- Large lathe parts

- High precision large parts

- Large prismatic parts
6-30 inch diameters from billets and forgings

Thin wall parts 6-3 inch diameter

6-60 inch machined box shapes, plates, braces, and assemblies

The first point to be made here is that each family of parts requires special consideration for setup reduction. Large thin-wall shapes require special design pot chucks or grease chucks to hold the shape while turning. If these types of tooling are not used, experience points out that the diameters will change as a result of both cutting tool pressures during cutting and clamping pressures during holding. In most cases, these special chucks cost $\$ 5000-15,000$ each and can only be used on one part because they must be machined to match that part geometry.

The second point to be made here is that each family of parts requires different equipment. That in turn requires different sundry supplies, chucks, cutting tools, holders, and setup wrenches.

In the 1988-1990 era, the miniature machining department had established six families of parts and designed work cells to accommodate each family. Machines were appropriated to specific families, and operators were identified for each family. This was one of the finest examples of moving to something approaching continuous flow manufacturing and cellular manufacturing. Just as equipment was about to be moved, the schedules for most of the ongoing parts evaporated and new products were introduced.

The above comments may sound as if there is little hope of improvements. That is not the case. A number of innovative improvements can be made. For example, some companies have used ice as a chucking tool. It is independent of part shape or size. However, its use requires changes in many aspects of a job. The secondary changes require more time and in turn have their own limitations. With a consistent product line, some of these innovations can be very effective.

A philosophical issue arises within some companies and within some countries. That philosophy is "If we cannot make major improvements in the entire operation, or do not have all the answers at this time, then we will not make a change." Many companies have now realized that significant change in one portion of the problem is worth implementing by itself.

\section{Setup Reductions Applicable to Machining}

Material availability, consistency, form, and size all can affect rapid setup. Over the years, FM\&T has looked at standard shapes and sizes, particularly to support development, and has standardized at least once. The following brief list describes material form and size improvements made. The list looks simple and short, but that belies the amount of effort it required to accomplish. With time, some of these efforts come unraveled a bit, and such efforts require occasional review. 


\section{Improvements in Material Issues}

1. Standardize material stock sizes.

2. Have a minimum quantity of standard material readily available to start a job.

3. Design part locating tabs on castings

\section{Work Holding Issues}

The major advances by industry in recent years in setup reduction involve work holding of prismatic parts such as milled shapes or castings and forgings. No advance of note was found for work holding of lathe parts, with the exception of Hirth couplings. The techniques available today include:

- Use modular fixture tooling

- Use standard tooling to tie fixtures to machines

- Use quick clamping

- - manual

- - power

- Use multiple part fixtures

- Use vacuum systems

- Use cryolanic glue

- Use multiple setups on each machine

Modular Tooling. In the 1950s, an English company introduced modular tooling with their Wharton tooling. FM\&T for many years used this system for some fixtures. Eventually, in the 1970 s or 1980s, it was removed from service. In the past five years at least 12 companies have begun producing modular tooling systems for prismatic parts. The basic approaches are similar, although there are unique ideas in each system. Some systems are ideal for castings and forgings that have irregular surfaces and widely varying dimensions. Others are more applicable to precision machined parts or parts having rectangular features. Carr Lane's Modular Fixturing Handbook is an excellent summary of one system. Other manufacturers including Precitec Corporation's SAFE system, Bluco, Stevens Engineering, Flexible Fixturing Systems, Qu-Co, Te-Co, Precision Systems, and Chick offer a full range system. None of these are applicable to high precision spherical parts.

These are relatively expensive systems, but for short run production, they reportedly pay for themselves within five to 10 uses. Since the fixture is normally dismantled after use, all the parts are recycled. The setup reduction advantage of this tooling is that it can be built in 1 to 4 hours so that tool design time is minimized and procurement or fabrication time is reduced dramatically.

Some if not all of these systems provide high precision, yet adjustments are available also if needed. 
The system components are not interchangeable between vendors. Because FM\&T machines both castings and rectangular products, two systems would be required to cover the range of products. Some companies also market different size systems for different size parts. Some of the components in one do not fit in the other.

Like any other new technology, these systems require that users be familiar with the possibilities and dedicated to supporting floor needs.

Some modular fixturing companies market limited range systems. One of the newer emphasis is the modularity of jaws for vicejaws. Chick Machine Tool, Schunk-Intec, Niki Swiss, Toolex, MiteeBite Products, and Turnmill Machining offer visejaw systems that can greatly accelerate part changeout and can at the same time accommodate different part designs in the same load. In these systems, part changeout and changeout between part designs are both in seconds.

Hirth couplings were introduced about 10 years ago to allow lathe chucks to be interchanged in seconds with repeatability of $0.000050 \mathrm{inch}$. That allowed lathes to become rapid changeover facilities. FM\&T does not have any Hirth coupling lathe systems. The original manufacturer also reportedly has gone out of business.

Standard Clamping of Fixture to Machine. One of the reasons for quick die changeout success was the conversion to standard wrenches, bolts, and clamping for dies. This same concept applies to machine tools. While standard tooling is available to do this, frequently many different size bolts, T-nuts, or related machine accessories are used, and each requires different storage and allows some confusion. This is not a new technology but rather a lack of rigor in good industrial engineering applications.

Quick Clamping. Several innovative quick clamp tool ideas are available today. High volume users can take advantage of power (hydraulic or pneumatic) clamps to lock parts or fixtures. Carr Lane, Jergens, and others offer these items.

High volume producers rely on multiple parts per load fixtures. Today, quick-change vise jaws are used for cylindrical as well as rectangular parts. Each of the companies named above provide vise jaw systems that can hold several parts of different sizes and shapes in a single load. Chick Machine Tool also provides rotating vise jaw fixtures for which each jaw holds several parts, and multiple jaws exist on each face being machined. The vises themselves also are generally quickly removed from tooling plates. These provide very inexpensive multiple part holding systems.

Mitee-Bite Products utilizes a unique offset head capscrew in a hexagonal washer. This allows the washer to slide sideways and clamp parts against a solid rail.

Vacuum Systems. FM\&T has relied on vacuum systems to hold flat parts on surface grinders. The vacuum plates perform well. Today, modular vacuum holders by S.B. Whistler are available that can clamp in three axes. 
Cryolanic Glue. One Missouri company claims to use methyl cyanoacylate (commonly referred to as super glue) exclusively for holding parts during machining. They give the parts a light but firm rap with a hammer to break to the bond then dissolve the glue with solvents. With machine probing or consistent shapes, this clearly is a fast and low cost fixturing approach. Dissolving the glue may not be fast and may not be environmentally as friendly as other methods of fixturing.

Multiple Setups on N/C Machine. Machining centers typically have enough bed space that one job can be run while another is being set up. As long as the risk of injury is low while making such a setup, the second setup would be performed internal to the machine cycle. As such, this represents a more effective use of machine time and produces more output than waiting until the machining is finished to initiate the setup. Significant potential for accidents can exist, however, depending on machine design, N/C program design, application, and operator training and awareness. In addition, users face the issues of flying chips and coolant, and fixtures are hard to mount while the table is moving.

\section{Cutting.Tool Issues}

Cutting tool issues fall into the following groups:

- Use of inserted toolbits

- Use of quick change tool holders

- Use of multiple toolbits in a setup

- Use of quick change tool posts

- $\quad$ Rapid tool setting

Quick Change Tool Holders. Quick change tool holders are available for many collet and chuck systems. There are approximately five different quick change cutting tool holder systems in use in the U.S. The FM\&T plant has two different systems. These quick change systems accommodate collet holders, drill chuck holders, straight shank tool holders, tap holders, floating holders, and taper shanks of each size. Shell mill holders, boring adapters, and fly cutter holders are also available in these series.

\section{Tool Positioning Issues}

For some machines, FM\&T has standardized which cutting tools go into which lathe turret positions. This facilitates setup and tape preparation because everyone knows automatically where the standard tools belong. The miniature machining department and the reservoir area are two facilities using this approach.

Many lathes do not provide a means for off-machine adjustment of cutting tool position relative to the face of the lathe chuck. As a result, each tool must be adjusted as close as possible by eyesight, then trial cuts or dial indicators are used to determine final positioning. While these operations may not take long, they do consume time and can result in a scrapped setup part. 
In the 1960s, the miniature machining department made a hinged collar which went around and underneath a Hardinge Chucker Lathe turret. The collar had a series of scribe lines about 0.050 inch apart which a machinist could look down to determine the approximate tool tip position. By taking a Polaroid or marking up a setup sheet, operators would have a quick visual reference to facilitate their work. The prototype was never used, but the reason it was not is not known at this time.

\section{Part Inspection Issues}

Machines can be programmed to accurately trace the correct path, and their individual axis accuracies and repeatability may be accurate. The resulting parts, however, may not agree with the programmed and expected dimensions because of tool deflection, part deflection, thermal effects in machine and part, or because of machine deflection under load. As a result, it is important to measure at least the first part off a new setup.

Small cylindrical parts can be measured easily at the machine with little loss of time. Contoured parts may require comparators, gages, or coordinate measuring machine inspections. Each of the inspection devices just mentioned can be located near machines, but accurate inspection requires close temperature control. CMMs, for example, and many large gages must be used in temperature controlled rooms.

Large parts will not fit on comparators. Parts with tolerances less than about 0.002 inches cannot be measured accurately on visual comparators. Gages are expensive and require months to obtain, and recalibration can require a long period of time. For rapid turnaround, gages are most desirable because these dedicated gages allow measurement in minutes. CMMs located in other departments or other rooms typically require hours or days to perform measurements depending on machine capacity and priority.

Table top CMMs are used by some shops for quick close measurements. Their use allows immediate data availability but requires a staff knowledgeable about CMM use. Improper use can cause major damage to a CMM and/or produce false or inaccurate measurements.

On-machine probing allows measurements of parts to be made on a machine. This approach can also compensate for temperature effects by using a known master size to master the probe. This approach does not account for the fact that fixturing or chucking can cause noticeable distortion. Part geometry and the holding mechanism determine whether or not distortion is likely to be a problem. For short run applications of high precision parts, on-machine probing may not be adequate. For continuous runs of the same part, history will provide a comfort level for how close the unrestrained (unclamped) results are to restrained (clamped) results.

Some new products will not use gages because of their expense and the time required to obtain them. Most dimensions are also not totally amenable to computers. Some dimensions may be verified by $\mathrm{CMMs}$, but others will require other means. Coordinate measuring machines are a fact of life for many new parts. Current research into software algorithms for accurate CMM results is 
finding useful production results which may make CMM results much more valid in the near future. FM\&T is a partner in some of this world class research.

\section{Machine Capabilities}

Some machines have several axes to produce features. A five-axis machining center can produce essentially any prismatic shape. All shops have a limited number of these capable machines. Their maintenance can be expensive and often requires long periods of down time. The ability to produce a part in a single setup greatly reduces setup time in most instances. FM\&T has one multi-axis lathe which allows multiple operations to be performed in a single setup.

There is a continual tradeoff between meeting machine capacity of these single-setup machines and using standard machines of lesser capability but more available capacity.

\section{Process Approaches}

Setups can be influenced by the sequence of operations chosen by the manufacturing engineer.

Renishaw, the manufacturer of inspection probes, has an exceptional plantwide approach to machining. They mill, turn, and inspect on machining centers via some unique fixturing, gauging, and measuring techniques. Their work has adapted standard machines to perform operations not normally completed on such equipment. They machine multiple parts per load and can accommodate parts of several designs in a single setup. It is the epitome of cycle time reduction, setup reduction, and machine loading. It is exceptionally well suited to ongoing production.

\section{Machine Dedication}

Users like to have machines dedicated to producing a single part or a close family of parts. It simplifies everyone's job. With certain machines, of which several copies exist, this is feasible.

\section{Unmanned Operation}

Few sites have unmanned operation. Those that do typically man one or two shifts and allow untended operation or minimally attended operation on other shifts. This does not really reduce setup time in the strictest sense, but it may allow rapid turnaround of repeat orders.

FM\&T does not have such operations, but the Flexible Manufacturing System at FM\&T has some reasonably universal tooling in the form of tombstones and vise tooling. While not designed initially to operate as a quick setup operation, it can do so for repeat orders. First run operations may require more time because of the more sophisticated operation. 


\section{Provisioning}

Setup reduction consists of reducing actual hands-on time in setup and reducing the machine time required to make the next setup. The first approach is value added; the second allows more parts per day but may not reduce manpower requirements.

Having every item required for a setup conveniently at a machine is a provisioning and timing issue. It allows the machine to produce parts more quickly but not necessarily with less labor.

Provisioning is an administrative issue rather than a technical issue and requires discipline to achieve. It generally is not more expensive than waiting until a task is finished before beginning to gather the materials for the next task. It may be faster.

When repeat orders are performed and it is known that orders will be repeated, shops typically prepare a kit of tools and leave them in a rack ready to be put on machine. FM\&T's heavy machining department has used this approach for many years. It requires more storage space and stage racks. When a job may not be run for months or years, this approach is not appropriate.

FM\&T engineering typically specifies all the tooling required for a job but does not specify machine clamps, T-nuts, locking bolts, washers, etc. Some companies specify all these so that every item can be readily available when needed. When all the machine accessories are located right at the machine and the choice is immediately obvious, no callout is needed.

\section{N/C Tape Issues}

Rapid setup on numerically controlled (N/C) machines requires raw material, cutting tools, tool holders, fixtures, verification items, machine, operator, instructions, and N/C tapes to complete a setup. When N/C tapes have errors, setups cannot be completed in a timely manner. N/C tape approaches can in some instances also make setup easier. Tool positioning consistently is a must.

\section{Maintenance of Machines and Tooling}

One assumes typically that the handy presence of a tool or availability of a machine implies that it is adequate. That is not necessarily the case. Machines that are not maintained adequately require longer setups because the part accuracy is not assured and constant "tinkering" by operators is necessary. This adds to time and frustrations.

A study of tool holders several years ago revealed that many tool holders being used were cracked or distorted. Others were new but failed to meet concentricity requirements. All of these led to longer setup time while machinists tried to discern the problem. Literally hundreds of holders were faulty. Tooling must be serviceable and meet its intended dimensions. The study found that manufacturers were not meeting their own tolerance on tool holders. More than one vendor was advertising a capability that was not delivered. 


\section{Setup Reduction Constraints for FM\&T Applications}

In today's environment, much of the machining work is development in nature and has no firm long-term requirement. Some long-term needs are measured as a "a few parts per year." Further, there are fewer clear families than there used to be.

The second restraint is that the viability of any production as an ongoing product is less assured than ever. What seems to be assured for two or three years disappears after six to twelve months.

New business brings new products of somewhat different setup families. It brings more products with immediate needs. The parts require the same high levels of quality and the same amount of careful planning and instruction.

Production machining at FM\&T utilizes over 200 machines of at least 100 different models. Each model typically has some uniqueness to either the cutting tool holders or the fixturing.

Some machines can be dedicated to a job because few other applications require their use or because multiple copies exist. In fact, at FM\&T several machines have been dedicated to an individual part or a family. Reservoirs as a family require the same machines and similar tooling. Rolamites have enough production to justify continuous or near continuous machine use.

All of FM\&T's machines could be fitted with special tooling to allow faster setups. The costs would be in the hundreds of thousands of dollars. If the families of products were consistent over time, as is the case for continuous production companies, clear economic benefits could be forecast. Specific machines that would best utilize such enhancements would also be clear.

\section{Cycle Time Improvements}

FM\&T has an ongoing emphasis on cycle time improvement. That encompasses setup reduction improvements. The reservoir production facilities are making a key effort, with a team working to reduce cycle time. Some work has already been initiated. Machining engineers from the inception worked as a team to utilize the same basic processing approaches. Similar cutting tools are used whenever possible.

Cutting tool engineers have worked for 10 years to reduce the variety of similar cutting tools in the FM\&T inventory. They have reduced the inventory variety by $50 \%$ and by at least 7000 total tool designs. They continue to emphasize standard tool usage and to provision tools accordingly. They have established a one-day turnaround time for ordering new tools. They have worked to reduce the number of defective tools received from the vendors. Each of these efforts enhances setup reduction. The right tool at the right time, which works as intended, is a concept essential to meeting this need.

The miniature machining department has pioneered the use of single operation machining. That is still used where possible, and for miniature parts it is often possible. 
The miniature machining department issued a "Preferred Tool Catalog" in 1990 which they continue to use. This 25 page document defines standard tools for the most commonly used machines in the department. It is applicable to both development and long run parts.

Both the miniature machining and the reservoir departments have used the "Universal Turret" concept of putting specific types of cutting tools at specific positions in a turret, so the turret can be readily set up for any job.

The precision machining and welding technology departments rearranged their departmental tooling cribs to better reflect the needs for quickly finding appropriate tools. They reorganized tooling to be located at the machine it was to be used on instead of in the crib. Tooling was clearly identified with large characters to facilitate identification. Guidelines for fixture storage and use were developed. The result was savings of 30 minutes or more per fixture for each setup.

Lighting in the crib was improved to allow ready identification of small items. A place was established for every tool and wrench.

In the late 1980s, hundreds of new tool holders were ordered to replace worn, damaged, and out-oftolerance tool holders. New machine bolts and washers were ordered to standardize on sizes and replace damaged or worn ones. Additional cutting tool moveable racks were ordered to allow kitizing of cutters. Holders were neatly filed in storage racks where everyone could readily find the appropriate one.

Setup reduction, like any significant improvement, requires significant effort to initiate. No one person "owns" a lathe or the overall processing approach in a department, no one owns the breadth of tooling used in a department, and no one person is responsible for all the parts in a department. No two operators have the same abilities, nor do any two machines have the same capabilities for accuracy and repeatability. The requirements, even within a single department, are challenging and require time, commitment, and extra levels of team building. A knowledge of future fabrication requirements or expectations is needed. Additional funds are required to accommodate some changes.

The process mapping effort now in work at FM\&T in conjunction with Black Belt solutions is yet another approach used to reduce setup time and cycle times. It allows all users an opportunity to document each variable in the process and provides a visual map to steps that can be improved. It is currently being used in machining, welding, marking, and other operations with some benefit to cycle time reduction. As problems are reduced, the need to make extra setups will also be reduced from this approach.

\section{ACCOMPLISHMENTS}

The state of the art of setup reduction has been summarized in this review. A number of FM\&T efforts have been described, but others have also been implemented. ${ }^{2}$ 


\section{FUTURE WORK}

No specific development project is planned to further reduce setup time. Individual efforts will continue on specific products and in specific departments. As special short run products come into being, they also will use some of the ideas highlighted in this review. 


\section{REFERENCES}

${ }^{1}$ LaRoux K. Gillespie, Fixturing and Handling of Miniature Parts, Kansas City Division: BDX-613-2558, April 1981 (Available from NTIS).

${ }^{2}$ R.W. Stiles, Quick Setup Technology, Kansas City Division: KCP-613-4620, March 1992 (Available from NTIS). 